\title{
ANALYSIS OF THE DYNAMICS OF FUNCTIONAL OCCLUSION INDICATORS IN THE CONSTRUCTION OF OCCLUSION SURFACES OF ORTHOPEDIC STRUCTURES
}

10.36740/WLek202012117

\author{
Svitlana P. Yarova', Sergii 0. Turchenenko' ${ }^{1}$, Iryna M. Tkachenko², Yuriy Yu. Yarov' \\ 'DONETSK NATIONAL MEDICAL UNIVERSITY, KRAMATORSK, UKRAIN \\ ¿UKRAINIAN MEDICAL STOMATOLOGICAL ACADEMY, POLTAVA, UKRAINE
}

\begin{abstract}
The aim: Is to evaluate the effectiveness of the proposed method of constructing occlusal surfaces of orthopedic structures by monitoring the dynamics of functional indicators of occlusion and the functional condition of the masticatory muscles.

Materials and methods: The object of the study was made up by 64 patients with included defects of the dentition of the 3rd class according to Kennedy. Patients were divided into two equal groups - the main group (patients were treated by using the suggested method of construction of occlusal surfaces of orthopedic structures) and control (dentition defects were replaced according to the traditional protocol).

Results: The results of evaluating the effectiveness of the proposed method showed that the index of symmetry of the anterior bundles of the temporal muscles dropped by $18.5 \%$, the index of symmetry of the masticatory muscles reduced by $22 \%$, the torque of the mandible reduced by $32 \%$, the index of stabilizing occlusal - by $27 \%$, relative efforts of balance disturbance for more than $10 \%$ regarding the left and right reduced by a factor of 4.4 , the rate of opening time was 1.5 times higher than before, the rate of time of opening of the jaws -1.8 times.

Conclusions: The use of the suggested method of orthopedic treatment with temporary structures leads to probable changes in the studied functional parameters in comparison with the control group $(\mathrm{p}<0,05)$.
\end{abstract}

KEY WORDS: occlusion relationship, masticatory muscle, orthopedic constructions

Wiad Lek. 2020;73(12 p. I):2651-2656

\section{INTRODUCTION}

Despite the ever-increasing aesthetic demand of patients, the effective restoration of the function of the dental-maxillary system (DMS) [1-5] remains an important requirement for orthopedic structures. Therefore, special attention should be paid to occlusal disorders that occur in the result of orthopedic treatment, as well as partial loss of teeth, which is accompanied by changes in almost all the parts of the dental apparatus and can provoke a number of complications. The most common and dangerous of them is development of musculoskeletal disorders. Numerous clinical studies have shown that lesions of the temporomandibular joint (TMJ) are revealed in $70-80 \%$ of the population and rank third after caries and periodontal disease [6-9].

It is a well-known fact that the basis for the formation of physiological occlusion is equal distribution of functional loads in cases of sufficient number of correctly placed occlusal contacts and adequate placement of TMJ components [10-12]. Modern methods of functional assessment of the condition of the masticatory muscles and occlusal relationships allow reaching the most adequate balance of the thyroid gland objectively in real time [13-16]. In connection with the above-mentioned facts, we consider it appropriate to develop the method of construction of occlusal surfaces of orthopedic structures which is based on monitoring and subsequent correction of the studied functional parameters of occlusion and masticatory muscle activity.

\section{THE AIM}

The aim is to evaluate the effectiveness of the proposed method of constructing occlusal surfaces of orthopedic structures by monitoring the dynamics of functional indicators of occlusion of T-Scan III Novus and the functional condition of the masticatory muscles BioEMG III with subsequent correction of the dynamic component of these parameters.

\section{MATERIALS AND METHODS}

The object of the study was made up by 64 patients with included defects of the dentition of the 3rd class according to Kennedy, not complicated by dental deformities, aged from 18 to 60 years. Criteria for inclusion of patients in the study were the following: the presence of informed consent to the study, violation of the integrity of the dentition in the area of premolars and molars, indications for permanent 
prosthetics. Criteria for exclusion of patients from the study were: the presence of removable prostheses, the presence of orthopedic structures based on dental implants, periodontal disease with signs of masticatory muscle hyperfunction, patients with TMJ pathology, lack of botulinum toxin therapy, muscle relaxants and / or tranquilizers.

At first, before treatment and during orthopedic structures setting, all the patients were tested using a device to determine the functional occlusion of T-Scan III Novus (Certificate of Registration №9887 / 2010, from 09.11.2010. Order of the Ministry of Health № 431, from 09.11.2010 UKTZED code: 90181990 00) and apparatus for assessing the functional state of the masticatory muscles BioEMG III (Certificate of registration: №11216 / 2012, dated 10.02.2012. Order of the Ministry of Health: № 86, dated 10.02.2012 , UKTZED code: 90184990 00. Manufacturer's name: BioResearch 42 Associated Inc., USA: Dental devices BioPac - register of medical equipment and medical devices). Determination of occlusion parameters was performed with the help of T-Scan III device, which defines and analyzes the force of tooth compression using ultra-thin sensors. T-Scan III technology is designed to perform dynamic determination of occlusion at all the stages of dental treatment and it is the only quantitative method of occlusion analysis used in practice. Diagnosis with the T-Scan III is very simple and painless. To determine the occlusal force, the patient must bite an individual plate - an ultra-thin sensor. At this time, all micromovements of the teeth are displayed on the computer monitor. The technology provides quantitative data on the strength and time of compression of the dentition. The data are obtained on two- and three-dimensional active diagrams, with the help of which it is possible to identify the problem points necessary for the further formation of the perfectly balanced occlusion and to do it quickly and accurately.

The methodology of research on the BioEMG III device is based on placing disposable electrodes on the previously degreased skin, these electrodes already have some electrically conductive gel in the projection of the motor points of the studied muscles. The obtained results are processed on a personal computer using special software (BioPACK BioRESEARCHAss Inc., USA), which allows to visualize and save the patient data immediately and quickly.

The use of the T-Scan III device in combination with the BioEMG III myograph makes it possible to determine the relationship between the electrical potential of the muscles and the occlusal relationships of the teeth.

With the help of these devices and the computer analysis the following functional indicators were studied: index of symmetry of the anterior bundles of temporal muscles, index of symmetry of the masticatory muscles, torque of the mandible, statically stabilizing occlusal index, relative efforts of balance disturbance for more than $10 \%$ regarding the left and right, indicators of closing and opening time.

According to the results of electromyographic examination, the following indices were calculated, they were suggested by Ferrario V. F., and now they are the basis of modern interpretation of data obtained by electromyography [16]:
1. Index of symmetry of the anterior bundles of the temporal muscles (POC TA):

POC TA $=$ (Average amplitude of the left temporal muscle / average amplitude of the right temporal muscle) $\mathrm{X} 100 \%$

Symmetry index of the anterior bundles of the temporal muscles, $\% 83 \leq(\%) \leq 100$

Result: value and sign, indicates the predominance of the right or left temporal muscle during the study;

2. Symmetry index of the masticatory muscles (POC $\mathrm{MM}$ ):

ROC MM = (Average amplitude of the left masticatory muscle proper $\backslash$ average amplitude of the right masticatory muscle proper) X 100\%

Chewing muscle symmetry index, $\% 83 \leq(\%) \leq 100$

Result: value and sign, indicates the predominance of the right or left masticatory muscle during the study;

3 . Torque of the lower jaw (TORS):

TORS = (Amplitude average of the left temporomandibular muscle + Amplitude average of the right proper masticatory muscle) $\backslash$ (Amplitude average of the right temporal muscle + Amplitude average of the left proper masticatory muscle) X 100\%

Lower jaw torque, $\% 90 \leq(\%) \leq 100$

Result: value, indicates possible displacement of the mandible horizontally when opening the mouth due to hyperactivity of the masticatory muscles;

4. Static stabilization occlusive index (BAR):

$\mathrm{BAR}=($ Average amplitude of the left temporomandibular muscle + average amplitude of the right temporal muscle) / (average amplitude of the right masticatory muscle + average amplitude of the left masticatory muscle) X100\%

Static stabilizing occlusal index, \% $90 \leq(\%) \leq 100$

Result: value and sign, indicates the predominance of masseterial or temporal type of chewing (horizontal means masseterial, vertical - temporal).

According to the results of digital analysis of occlusiograms, the following indices were registered: relative efforts of balance disturbance for more than $10 \%$ regarding the left and right, indicators of closing and opening time.

Patients were divided into two equal groups - the main group (patients were treated by using the suggested method of construction of occlusal surfaces of orthopedic structures) and control (dentition defects were replaced according to the traditional protocol). Orthopedic constructions for patients of the main group were performed on the basis of provisional constructions that met the needs of restoring proper articulation, muscle balance and muscle activity. Patients underwent construction of occlusal surfaces of orthopedic structures under monitoring of the dynamics of functional indicators of occlusion and the functional state of the masticatory muscles with subsequent correction of the dynamic component of these parameters. The comparison group included 15 people with intact dentitions. The study groups were randomized by sex, age, type of dentition defect.

It should be taken into consideration that in both the main and control groups, all the orthopedic structures were manufactured using the facial arch and individual 
Table I. Monitoring parameters of electromyographic examination in the process of orthopedic treatment ( $M \pm S E)$

\begin{tabular}{|c|c|c|c|c|c|}
\hline Tes & oups & $\begin{array}{c}\text { Symmetry index } \\
\text { of the anterior bundles } \\
\text { of the temporal } \\
\text { muscles, \% }\end{array}$ & $\begin{array}{c}\text { Symmetry } \\
\text { index of the of } \\
\text { massicatory } \\
\text { muscles, \% }\end{array}$ & $\begin{array}{l}\text { Torque of the } \\
\text { lower jaw, \% }\end{array}$ & $\begin{array}{c}\text { Statically } \\
\text { stabilizing } \\
\text { occlusive index \% }\end{array}$ \\
\hline \multirow{2}{*}{$\begin{array}{c}\text { Control } \\
n=32\end{array}$} & Before treatment & $59 \pm 5 »$ & $70 \pm 5 »$ & $62 \pm 5 »$ & $66 \pm 5 »$ \\
\hline & After treatment & $75 \pm 2^{*}$ & $80 \pm 2^{*}$ & $76 \pm 2^{*}$ & $70 \pm 2^{*}$ \\
\hline \multirow{3}{*}{$\begin{array}{l}\text { Main group } \\
\quad n=32\end{array}$} & Before treatment & $58 \pm 5 »$ & $71 \pm 5 »$ & $61 \pm 5 »$ & $66 \pm 5 »$ \\
\hline & Diagnostic tests & $91 \pm 2$ & $90 \pm 2$ & $90 \pm 2$ & $90 \pm 2$ \\
\hline & After treatment & $92 \pm 2$ & $90 \pm 2$ & $92 \pm 2$ & $91 \pm 2$ \\
\hline $\begin{array}{l}\text { Compari-son } \\
\text { group } n=15\end{array}$ & & $90 \pm 6$ & $91 \pm 7$ & $94 \pm 3$ & $93 \pm 3$ \\
\hline
\end{tabular}

Note: * $p>0,05$ against the control group;

«- $p>0,05$ against the comparison group

Table II. Parameters of digital occlusiography monitoring in the process of orthopedic treatment $(\mathrm{M} \pm \mathrm{SE})$

\begin{tabular}{|c|c|c|c|c|}
\hline \multicolumn{2}{|c|}{ Groups of research } & \multirow{2}{*}{$\begin{array}{l}\text { Relative efforts of balance } \\
\text { disturbance for more than } 10 \% \\
\text { regarding the left and right, }\end{array}$} & \multirow{2}{*}{$\begin{array}{c}\begin{array}{c}\text { Time indicators } \\
\text { of jaw closing, } C\end{array} \\
0,6 \pm 0,43 »\end{array}$} & \multirow{2}{*}{$\begin{array}{c}\begin{array}{c}\text { Time indicators } \\
\text { of jaw opening, } C\end{array} \\
0,68 \pm 0,8 »\end{array}$} \\
\hline Control & Before treatment & & & \\
\hline $\mathrm{n}=32$ & After treatment & $23 \pm 0,9 *$ & $0,512 \pm 0,4 *$ & $0,589 \pm 0,3 *$ \\
\hline \multirow{3}{*}{$\begin{array}{l}\text { Main group } \\
\quad n=32\end{array}$} & Before treatment & $25 \pm, 05 »$ & $0,59 \pm 0,5 »$ & $0,61 \pm 0,5 »$ \\
\hline & $\begin{array}{l}\text { Diagnostic tests on } \\
\text { provisional constructions }\end{array}$ & $5,8 \pm 0,7$ & $0,4 \pm 0,24$ & $0,3 \pm 0,29$ \\
\hline & After treatment & $5,2 \pm 0,5$ & $0,343 \pm 0,3$ & $0,32 \pm 0,2$ \\
\hline $\begin{array}{l}\text { Comparison } \\
\text { group } n=15\end{array}$ & & $2,1 \pm 0,55$ & $0,305 \pm 0,15$ & $0,313 \pm 0,11$ \\
\hline
\end{tabular}

Note: ${ }^{*}-p>0,05$ against the control group;

$\ll-p>0,05$ against the comparison group

articulators for maximum accuracy and anatomical and physiological compliance. Statistical processing of the obtained digital data was performed using the computer program Statistica 8.0 (STA862D175437Q). For each sample set of observations ( $\mathrm{n})$, the arithmetic mean $(\mathrm{M})$, the standard error of the mean (SE), the standard deviation (SD), and the $95 \%$ confidence interval of the true mean were calculated using the Student's t-test. The level of significance of the mean values in the independent samples (p) was calculated according to the distribution function of the Student's t-test: at $\mathrm{p}<0.05$ - the difference is significant; $\mathrm{p}>0.05$ - the difference is not significant.

\section{RESULTS}

The results of the electromyographic study (Table I) showed that in the comparison group (without dentition defects) the symmetry index of the anterior bundles of the temporal muscles was $90 \% \pm 6$, the symmetry index of the masticatory muscles was $91 \% \pm 7$, the torque of the mandible $-94 \% \pm 3$, statically stabilizing occlusal index $-93 \% \pm 3$. These values of the studied parameters indicate balanced and regulate activity of the masticatory muscle complex.

Analysis of digital occlusiograms in patients of the comparison group (Table II) showed that the value of relative efforts of balance disturbance for more than $10 \%$ regarding the left and right was determined at $2.1 \% \pm 0.55$, the time of closure of the jaws was $0.305 \mathrm{~s} . \pm 0.15$, and the opening time indicator is $0.313 \mathrm{~s} . \pm 0.15$. The obtained data indicate a functionally correct occlusal correlation relation of the dentition.

Monitoring the results of the initial functional state of the masticatory muscles and the correlation of dentition in patients of the control group with dentition defects (Kennedy class III), not complicated by dental deformities showed significantly different results $(p<0.05)$ from the comparison groups, which showed clear violations of occlusal relations. The parameters of electromyographic and occlusiographic examination, as can be seen from tables I and II, were as follows: the index of symmetry of the bundles of the anterior temporal muscles was, on average, $35 \%$ less than that without deformations of the dentition, the index of symmetry of the masticatory muscles was $24 \%$ less, the torque of the mandible was $34 \%$ less, the static index stabilizing occlusal was $29 \%$ less, relative efforts of balance disturbance for more than $10 \%$ regarding the left and right, was 11.9 times more, the time of closing the jaws was 1.2 times more, the time of opening the jaws was 2.2 times more $(p<0,05)$. It should be taken into consideration that the initial values of these indicators in the main group (Fig. 1) were proportional to those in the 


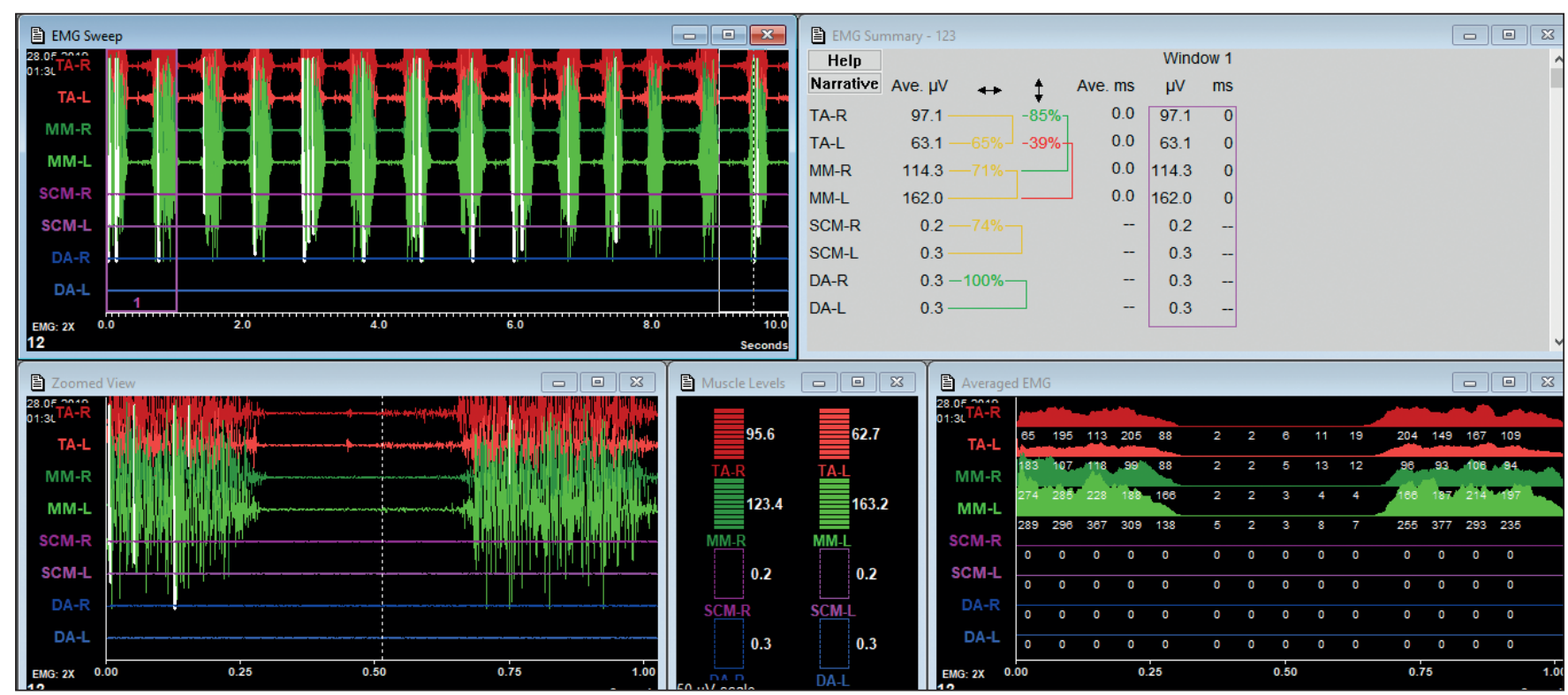

Fig. 1. 30 years-old patient M's myography (the main group, before treatment)

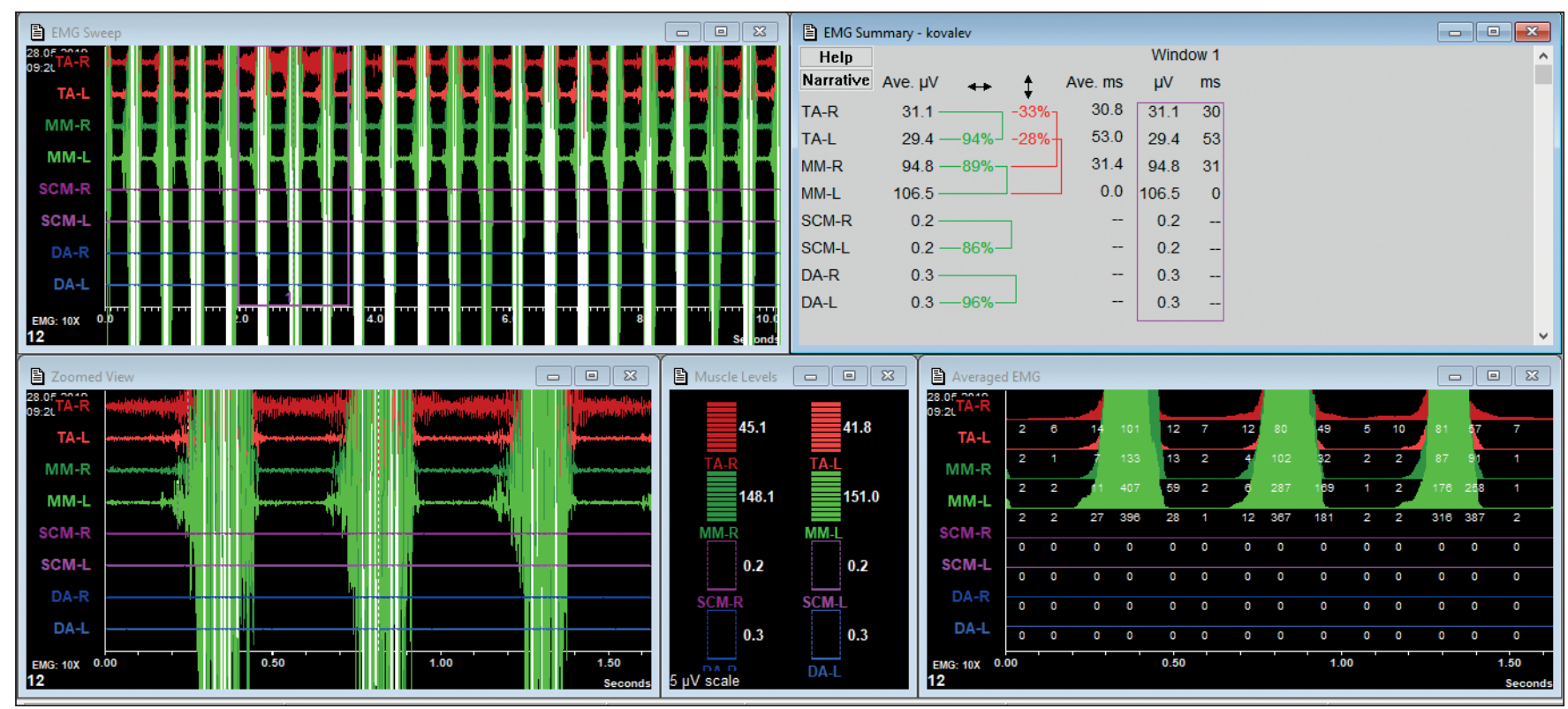

Fig. 2. 30 years-old patient M's myography (the main group, on the provisional constructions)

control ( $p>0.05$ ), which makes it possible to compare them further, and probably differ from such comparison groups $(\mathrm{p}<0.05)$. In the main group, a comparative evaluation of the values of diagnostic samples on makeshift structures was carried out according to the studied parameters in relation to the initial values (Table I,II; Fig. 2,3). Thus, the index of symmetry of the anterior bundles of the temporal muscles decreased by $36 \%$, the index of symmetry of the masticatory muscles - by $21 \%$, the torque of the mandible - by $32 \%$, the index of statically stabilizing occlusal - by $26 \%$, relative efforts of balance disturbance for more than $10 \%$ regarding the left and right, increased 4 times, the rate of closing the jaws -0.6 times, the time of opening -2 times $(\mathrm{p}<0,05)$. It is worth mentioning that these values of functional parameters reached values commensurate with those in the comparison group ( $\mathrm{p}>0.05)$.

The results of evaluating the effectiveness of the proposed method on the dynamics of functional indicators of myoand occlusiography showed that their values in the main and control groups after orthopedic treatment had significant differences $(\mathrm{p}<0.05)$. Namely: the index of symmetry of the anterior bundles of the temporal muscles dropped by $18.5 \%$, the index of symmetry of the masticatory muscles reduced by $22 \%$, the torque of the mandible reduced by $32 \%$, the index of stabilizing occlusal - by $27 \%$, relative efforts of balance disturbance for more than $10 \%$ regarding the left and right reduced by a factor of 4.4 , the rate of opening time was 1.5 times higher than before, the rate of time of opening of the jaws -1.8 times. 


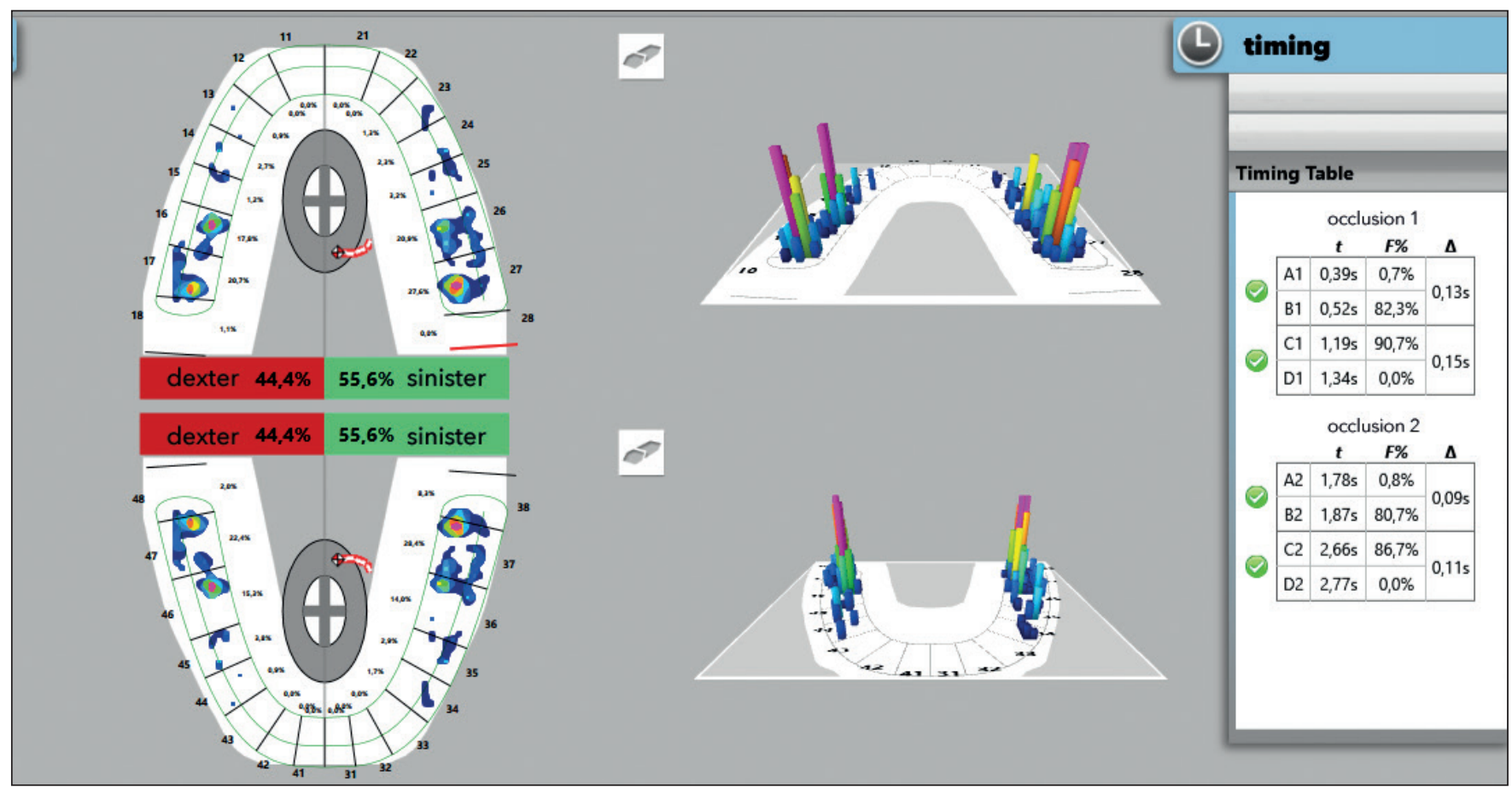

Fig. 3. 30 years-old patient M's digital occlusiography (the main group, on the provisional constructions, )

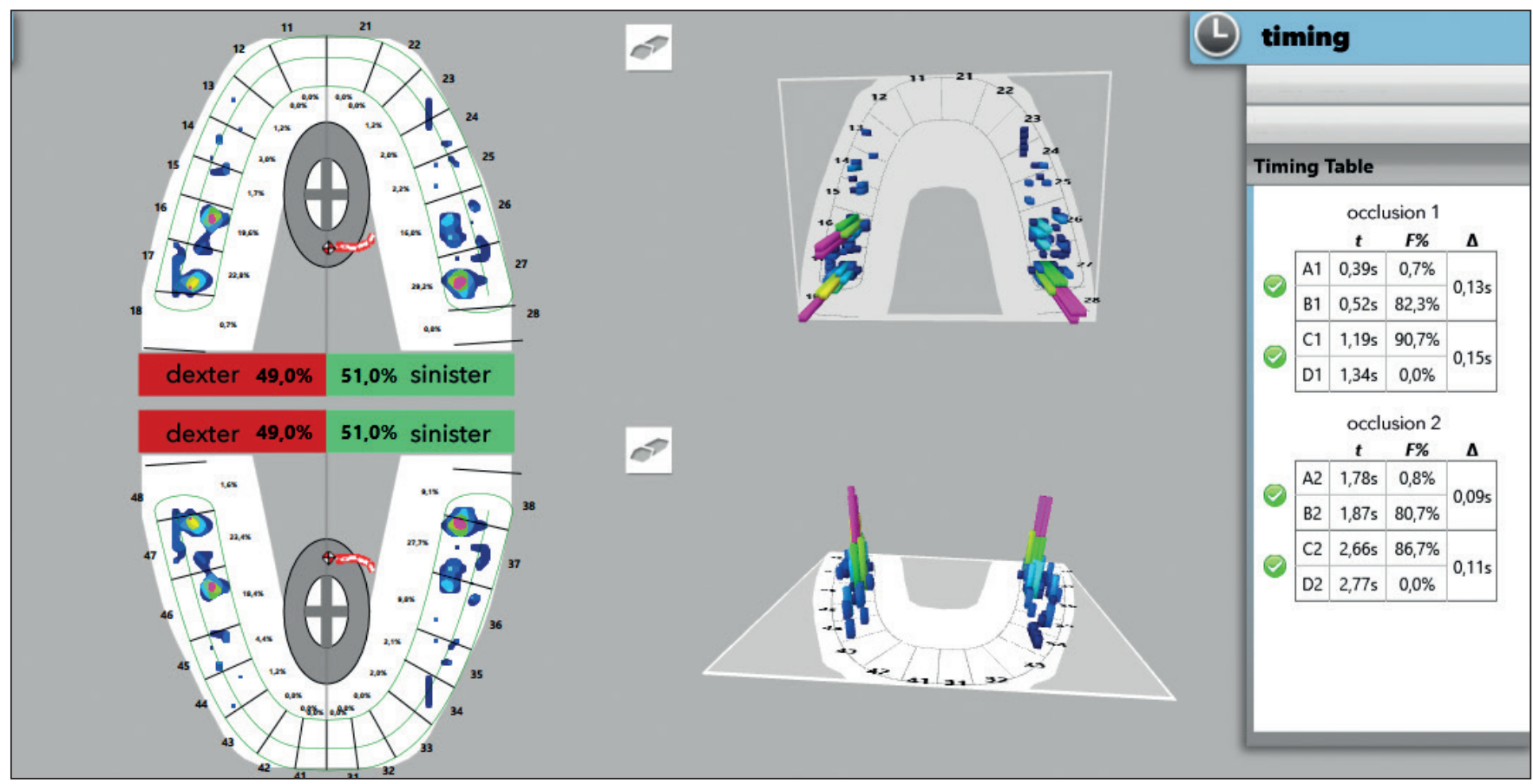

Fig. 4. 30 years-old patient M's digital occlusiography (the main group, after treatment)

The obtained results indicate the normalization of functional parameters when using the proposed method of constructing occlusal surfaces immediately after treatment (Fig. 4).

\section{DISCUSSION}

Until now, in orthopedic treatment, methods of restoring masticatory efficiency have taken into account only the qualitative indicators that characterize the condition of the dental-maxillary system. Quantitative monitoring of the dynamics of functional indicators of occlusion of T-Scan III Novus and the functional state of the masticatory muscles BioEMG III with subsequent correction of the dynamic component of these parameters allowed to achieve a positive clinical effect, which was manifested by the normalization of these indices.

This goal was achieved through the application of the proposed method of construction of occlusal surfaces of 
makeshift structures. The study of the condition of occlusal relations in patients with included defects of the dentition is reasonable and is preconditioned by the high prevalence and complexity of the diagnosis of functional disorders. The combined usage of myo- and occlusiography methods at different stages of orthopedic treatment is considered appropriate and promising.

The study of the condition of occlusal relations in patients with included defects of the dentition is reasonable and it is preconditioned by the high prevalence and complexity of the diagnosis of functional disorders. The combined usage of myo- and occlusiography methods at different stages of orthopedic treatment is considered appropriate and promising.

\section{CONCLUSIONS}

1. The combination of applied diagnostic methods of myo- and occlusiography makes it possible to assess the functional parameters of the masticatory apparatus in an objective way.

2. The use of the suggested method of orthopedic treatment with temporary structures leads to probable changes in the studied functional parameters in comparison with the control group $(\mathrm{p}<0,05)$.

3. The obtained values of myo- and occlusiography indicators after the proposed treatment are commensurate with those in the comparison group (without dentition defects), which proves their normalization.

\section{REFERENCES}

1. Nespriadko V.P., Moroz Yu.lu., Lyseiko N.V. Stan okliuziinykh spivvidnoshen u period adaptatsii do neznimnykh zubnykh proteziv [State of occlusion relations in the period of adaptation of patients to non-removable dentures].Bukovynskyi medychnyi visnyk. 2017;2(82):42-46. (in Ukrainian).

2. Moroz lu.lu., Nespriadko V.P., Lusiuk S.V. Dynamyka yzmenenyia sostoianyia zhevatelnukh mushts y okkliuzyonnukh sootnoshenyi zubnukh riadov v rannye y otdalennue sroky protezyrovanyia patsyentov nes' emnumy zubnumy protezamy [Dynamics of changes in the state of the masticatory muscles and occlusal ratios of the dentition in the early and late periods of prosthetics of patients with fixed dentures]. Moderni vẽda. 2018;1:112-120. (in Ukrainian).

3. Bida 0.V. Patolohichni zminy okliuzii, obumovleni chastkovoiu vtratoiu zubiv, uskladnenoiu zuboshchelepnymy deformatsiiamy [Restoration of normal occlusal relationships in the complex treatment of patients with generalized periodontitis with included dentition defects]. Visnyk stomatolohii. 2016;4: 34-37. (in Ukrainian).

4. Zhehulovych Z.Ye. Klinichna kharakterystyka dentalnoi okliuzii pislia vidnovlennia u konformatyvnomu pidkhodi [Clinical characteristics of dental occlusion after recovery in the conformational approach]. Novyny stomatolohii. 2015; 2(83): 18-23. (in Ukrainian).

5. Fedorova 0.V. Mozhlyvosti vykorystannia systemy komp'iuternoho analizu okliuziinykh kontaktiv pry ortopedychnomu likuvanni patsiientiv iz vtorynnymy zuboshchelepnymy deformatsiiamy (ohliad literatury) [Possibilities of the use of the system of computer analysis of occlusal contacts during orthopedic treatment of patients with secondary dento-facial deformations (review of literature)]. Ukrainskyi stomatolohichnyi almanakh. 2017;3: 49-52. (in Ukrainian).
6. Kerstein R. B. Handbook of Research on Computerized Occlusal Analysis Technology Application in Dental Medicine. Global Book series.AMTCP.2015.

7. Bida 0. V. Patolohichni zminy okliuzii, obumovleni chastkovoiu vtratoiu zubiv, uskladnenoiu zuboshchelepnymy deformatsiiamy [Pathological changes of occlusion caused by partial losses of teeth, complicated by teeth deformations]. Visnyk stomatolohii. 2016; 4:34-37. (in Ukrainian).

8. Afrashtehfar K.I., Qadeer S. Computerized occlusal analysis as an alternative occlusal indicator. Cranio. 2016;34:52-57. doi: https://doi. org/10.1179/2151090314Y.0000000024

9. Klineberg I., Eckert S. Functional Occlusion in Restorative Dentistry and Prosthodontics. 1st ed. Mosby. 2016: 288.

10. Nelson S. Wheeler's Dental Anatomy, Physiology and Occlusion. 11th ed. Elsevier. 2019: 336.

11. Okeson JP. Management of Temporomandibular Disorders and Occlusion. 8th ed. Mosby. 2019: 51.

12. Amin K., Vere J., Thanabalan N., Elmougy A. Occlusal concepts and considerations in fixed prosthodontics. Primary Dental Journal. 2019; 8 (3): 20-27.

13. Cerna M., Ferreira R., Zaror C., Navarro P. Validity and reliability of the T-Scan III for measuring force under laboratory conditions. The Journal of Oral Reabilitation. 2015; 42: 544-551.

14. Buduru S., Mesaros A., Talmaceanu D., Baru 0. et al. Occlusion in the digital era: a report on three cases. Medicine and Pharmacy Reports. 2019; 92 (3): 78-84.

15. Afrashtehfar K. I., Qadeer S. Computerized occlusal analysis as an alternative occlusal indicator. Cranio. 2016; 34 (1): 52-57.

16. Drohomyrets'ka M. S., Bilous M. K., Kushpela Y.I., Voytovych O. A. Craniopostural adaptation in orthodontic patients. Zbirnyk naukovykh prats' spivrobitnykiv NMAPO imeni P. L. Shupyka. 2015; 24 (1): 505-509.

\section{ORCID and contributionship:}

Svitlana P. Yarova: 0000-0002-7830-4579 C

Sergii O. Turchenenko: 0000-0002-0396-357X ${ }^{A, E}$,

Iryna M. Tkachenko: 0000-0001-8243-8644 ${ }^{D, F}$

Yuriy Yu. Yarov: 0000-0002-2867-9866 ${ }^{B}$

\section{Conflict of interest:}

The Authors declare no conflict of interest.

\section{CORRESPONDING AUTHOR \\ Iryna M. Tkachenko}

Ukrainian Medical Stomatological Academy

23 Shevchenko st., 36011 Poltava, Ukraine

tel: +380505353181

e-mail: tkachenkoirmix@gmail.com

Received: 09.07 .2020

Accepted: 20.11.2020

A - Work concept and design, B - Data collection and analysis, C - Responsibility for statistical analysis,

D-Writing the article, $\mathbf{E}$-Critical review, $\mathbf{F}$ - Final approval of the article 